\title{
Effects of Aminooxy Analogues of Biogenic Polyamines on Aggregation and Stability of Calf Thymus DNA
}

\author{
F. J. RAMÍREZ, ${ }^{1}$ T. J. THOMAS, ${ }^{2}$ T. ANTONY, ${ }^{3}$ J. RUIZ-CHICA, ${ }^{1}$ T. THOMAS $^{4}$ \\ ${ }^{1}$ Department of Physical Chemistry, University of Málaga, Málaga 29071, Spain \\ ${ }^{2}$ Department of Medicine and Cancer Institute of New Jersey, University of Medicine and Dentistry of New Jersey, \\ Robert Wood Johnson Medical School, New Brunswick, New Jersey 08903 \\ ${ }^{3}$ Department of Molecular Biology, Max Planck Institute for Biophysical Chemistry, Am Fassberg 11, \\ D-37077 Goettingen, Germany \\ ${ }^{4}$ Department of Environmental \& Community Medicine, Environmental and Occupational Health Sciences Institute, and \\ Cancer Institute of New Jersey, University of Medicine and Dentistry of New Jersey, Robert Wood Johnson Medical \\ School, New Brunswick, New Jersey 08903
}

Received 25 January 2002; revised 11 March 2002; accepted 25 March 2002

\begin{abstract}
The effect of a series of aminooxy analogues of the biogenic polyamines spermidine and spermine on the conformation of calf thymus DNA is studied. These new molecules are isosteric and charge insufficient analogues that are suitable to study the roles of both charge distribution and structural requirements in the molecular physiology of the biogenic polyamines. They are also evidenced as useful tools to inhibit polyamine biosynthesis and cell growth. Circular dichroism (CD) spectra of solutions containing DNA and the aminooxy analogues at different concentrations (100-1000 $\mu M$ ) and different $\mathrm{pH}$ values, (5-7.5) are recorded. We use both sonicated and highly polymerized calf thymus DNA. The CD spectra of sonicated DNA showed the formation of $\Psi$-DNA, a highly ordered aggregated structure similar to liquid crystals, in the presence of the aminooxy analogues. Aggregation induced by an aminooxy derivative of spermine is followed by DNA collapse when increasing the polyamine concentration. The features of $\Psi$-DNA are not detected for highly polymerized DNA. Temperature melting measurements support a high degree of structural order of the aggregates. The CD experiments indicate that dications are unable to induce major changes on the macromolecular structure of DNA. In addition, aggregation is only observed when the trimethylene moiety is present between two adjacent positive charges. The observed differences among the CD spectra of DNA solutions with different aminooxy derivatives of spermidine indicate different roles for different amino groups of this biogenic polyamine when interacting with DNA. Our results support the idea that aminooxy analogues can be used as good models in studying the physiological functions of biogenic polyamines. (C) 2002 Wiley Periodicals, Inc. Biopolymers (Biospectroscopy) 65: 148-157, 2002
\end{abstract}

Keywords: aminooxy; polyamine; DNA; circular dichroism aggregated

\section{INTRODUCTION}

The biogenic polyamines putrescine, spermidine, and spermine are ornithine-derived organic poly-

Correspondence to: F. J. Ramírez (ramirez@uma.es).

Contract grant sponsor: Spanish Ministry of Science and Technology (to F.J.R. and J.R.C.); contract grant number: BQU3000-1435-C03-03.

Contract grant sponsor: Public Health Service; contract grant numbers: CA42439, CA73058, CA80163.

Biopolymers (Biospectroscopy), Vol. 65, 148-157 (2002)

() 2002 Wiley Periodicals, Inc. cations involved in a wide variety of biological functions. ${ }^{1-3}$ They are present in all living organisms, from microorganisms to superior animals, where they act as metabolic regulators in cell proliferation and differentiation and as agents that stabilize nucleic acid structure and conformation. ${ }^{3-6}$ Polyamines are known to protect DNA from external agents, such as reactive oxygen species or radiation. ${ }^{7,8}$ Efforts were made in the past to explain how the polyamines bind to nucleic acids supported different proposals for the 
DNA polyamines interaction, from purely electrostatic models ${ }^{9,10}$ to those largely based on structural specificities. ${ }^{11,12}$ Raman spectroscopy was recently applied to obtain new data about this question, and several preferential binding models were proposed. ${ }^{13-15}$

From extensive research directed toward the understanding of the interaction between nucleic acids and the polyamines, it seems clear that molecular charge and the polyamine structure are the two essential factors in these interactions. In short, the biological functions and activities of polyamines are determined by the molecular geometry, which is largely the location of positively charged nitrogen atoms; the nature of the linkages between these nitrogen atoms; and the degree of these charges. The latter is well illustrated by the discovery of tertiary and quaternary polyamines in thermophilic bacteria. ${ }^{16}$

A suitable way to study the role of these factors is the use of structural analogues of biogenic polyamines. In the last few years, a series of isosteric analogues of putrescine, spermidine, and spermine were synthesized by replacing the terminal aminomethylene group with an aminooxy $\left(\mathrm{H}_{2} \mathrm{NO}-\right)$ one, ${ }^{17,18}$ which made the analogues insufficiently protonated at physiological $\mathrm{pH}\left(\mathrm{p} K_{a}\right.$ of the aminooxy group is about 5 ). This replacement also converted putrescine, spermidine, and spermine into typical carbonyl reagents. These aminooxy derivatives were demonstrated to be useful tools to inhibit polyamine biosynthesis and to investigate the peculiarities of the functional structure of polyamines. Thus, the aminooxy analogue of putrescine, 1-aminooxy-3-aminopropane (APA), turned out to be an effective inhibitor of ornithine decarboxylase both in vitro and in cultured cells. ${ }^{19,20}$ The aminooxy analogues of spermidine and spermine 7-[(amino)oxy]-4aza-1-aminoheptane trihydrochloride (APAPA), 7-[(amino)oxy]-5-aza-1-aminoheptane trihydrochloride (AOEPUT), and 11-[(amino)oxy]-4,9diaza-1-aminoundecane tetrahydrochloride (AOSPM) were proved as inhibitors or substrates of the enzymes involved in methionine and polyamine metabolism. ${ }^{21}$ These analogues were capable of penetrating inside cells, had low cytotoxicity, regulated catabolic stability, and inhibited cell growth in a cell-type specific manner. ${ }^{22,23}$

In the present study we used circular dichroism (CD) spectroscopy to investigate the effect of three aminooxy analogues of biogenic polyamines (Fig. 1) on the conformation of calf thymus (CT) DNA. APAPA and AOEPUT are isosteric with<smiles>CCCCC[NH2+]CCCNOCCCN</smiles><smiles>NOCC[NH2+]CCCC[NH3+]</smiles>

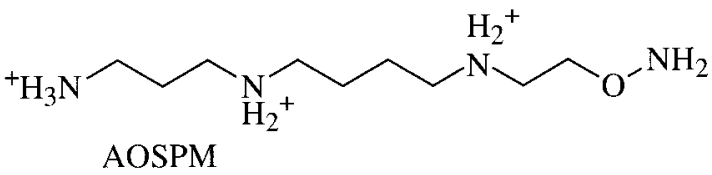

Figure 1. The chemical structures of the polyamine aminooxy analogues under study.

spermidine, AOSPM is isosteric with spermine, and all of them are charge insufficient analogues; they are therefore suitable molecules to analyze the structure-activity relationships of the biogenic polyamines. On the other hand, the $\mathrm{p} K_{a}$ of an aminooxy group is about 5 , so that APAPA and AOEPUT are dications at physiological $\mathrm{pH}$ and AOSPM is a trication. The three molecules would increase their positive charge by decreasing the $\mathrm{pH}$, which can be used to control the charge distributions of spermidine and spermine without changing the molecular topology significantly.

\section{MATERIALS AND METHODS}

\section{DNA and Aminooxy Analogues}

Highly polymerized (HP) CT-DNA was purchased from Worthington Biochemicals (Freehold, NJ). The The ratio of the absorbance at $260 \mathrm{~nm}$ versus that at $280 \mathrm{~nm})\left(A_{260} / A_{280}\right)$ was 1.88 , indicating that the DNA was free of protein contamination. Short DNA fragments were prepared by ultrasonication ${ }^{24}$ using a Branson Sonicator (Branson Ultrasonics Corp., Danbury, CT). The average molecular size, which was checked by gel electrophoresis, was about $150 \mathrm{bp}$. The sonicated DNA was extensively dialyzed against $10 \mathrm{~m} M$ Tris buffer. The final concentration was determined by measuring the absorbance at $260 \mathrm{~nm}$ and using a molar extinction coefficient of $6900 \mathrm{~mol}^{-1} \mathrm{~cm}^{-1}$.

Details of the synthesis of the AOEPUT, APAPA, and AOSPM aminooxy analogues of the biogenic polyamines are given elsewhere. ${ }^{17,23}$

Solutions at different aminooxy concentrations were prepared for both sonicated and unsonicated 
CT-DNA. The DNA concentration was always $5.86 \times 10^{-5} M$, as obtained from an $A_{260}$ of 0.4043 optical density. For each aminooxy concentration, different $\mathrm{pH}$ values were adjusted using hydrogen chloride. Samples were kept at $4^{\circ} \mathrm{C}$, and the CD spectra were recorded $2 \mathrm{~h}$ after preparing the solutions.

\section{Electronic Spectroscopy}

The CD spectra were recorded at room temperature $\left(22^{\circ} \mathrm{C}\right)$ in an AVIV 62DS CD spectrometer (AVIV Associates, Lakewood, NJ). A 1-cm pathlength quartz cell was used for all measurements. The spectra were recorded after buffer correction. The CD spectra corresponded exclusively to DNA, because none of the aminooxy analogues had measurable CD signals. The molar ellipticity, $[\Theta]$, was calculated from the equation

$$
[\Theta]=\frac{\Theta}{c \times l}
$$

where $\Theta$-is-the ellipticity, $c$ is the DNA molar concentration, and $l$ is the cell pathlength $(\mathrm{cm}) .^{25}$ Melting experiments were performed using a Beckman DU 640 spectrophotometer supplied with a sample block for six cells. The temperature range was $30-100^{\circ} \mathrm{C}$ at a rate of $0.5^{\circ} \mathrm{C} / \mathrm{min}$. The $A_{260}$ was measured simultaneously for the complete block after thermal equilibrium was reached. The melting temperature $\left(T_{m}\right)$ was obtained by computing the first derivative of the absorbance versus the temperature curve. The $T_{m}$ value thus determined was comparable to that derived from the midpoint of the absorbance versus temperature curve, and the reproducibility was $\pm 0.5^{\circ} \mathrm{C}$ in repeated measurements of the same sample. Melting experiments were performed at physiological $\mathrm{pH}$ (7.5) using the same stock solution as for the CD experiments.

\section{RESULTS}

\section{Spermine Aminooxy Analogue AOSPM}

Figure 2 shows the CD spectra of sonicated CTDNA with $10 \mathrm{~m} M$ Tris- $\mathrm{HCl}$ in the presence of different concentrations of AOSPM at $\mathrm{pH} 5,6,7$, and 7.5. At each $\mathrm{pH}$ the $\mathrm{CD}$ spectrum showed the standard features of a B-DNA conformation with positive peaks at 222 (weak) and $276 \mathrm{~nm}$ (strong) and a negative peak at $246 \mathrm{~nm}$ (strong). All of these bands were assigned to $\pi \rightarrow \pi^{*}$ electronic transitions, although the positive strong band could also have some $n \rightarrow \pi^{*}$ contribution. ${ }^{26}$ No major changes were detected in the CD spectrum of sonicated CT-DNA with changes in the $\mathrm{pH}$ within the range studied.

The CD spectrum of DNA with AOSPM at pH 5 [Fig. 2(A)] showed a dramatic increase in molar ellipticity, when increasing the aminooxy polyamine concentration, of the band at $276 \mathrm{~nm}$, which was accompanied by a redshift of about 10 $\mathrm{nm}$. The positive DNA band at $222 \mathrm{mn}$ also exhibited an intensity increase and blueshift in the presence of this aminooxy polyamine. Maximum changes were observed when the concentration of AOSPM was $250 \mu M$. At concentrations higher than $250 \mu M$, the intensity of the CD signal decreased, being negligible at a AOSPM concentration of $1000 \mu M$. This observation is indicative of DNA collapse, as was easily visible from the appearance of a solid precipitate. In some of these spectra the ellipticity did not approach zero in the $350-\mathrm{nm}$ region. This may be due to differential scattering of right- and left-handed polarized light by condensed DNA particles. ${ }^{27}$

When the $\mathrm{pH}$ of the solution was increased, the following features were observed. The maximum increase in the ellipticity occurred in all cases at an AOSPM concentration of $250 \mu M$. At $\mathrm{pH} \mathrm{6,a}$ solid phase was observed when the aminooxy polyamine concentration reached $1000 \mu M$. Solutions at higher $\mathrm{pH}$ values did not exhibit any precipitation phenomena within the range of concentrations studied. As can be observed in Figure $2(\mathrm{C}, \mathrm{D})$, the CD spectra from solutions at 500 and $1000 \mu M$ aminooxy polyamine concentrations still showed increases in the molar ellipticity, compared to the CD spectrum of control CT-DNA. In addition, the intensity of the band at $276 \mathrm{~nm}$ increased with increasing $\mathrm{pH}$ at a $250 \mu M$ AOSPM concentration.

The CD spectra of HP CT-DNA at identical experimental settings were also studied. The results are depicted in Figure 3. The spectra did not exhibit noticeable changes in relation to the change of the $\mathrm{pH}$. As can be observed, there were no variations in the molar ellipticity at AOSPM concentrations lower that $250 \mu M$; at $500 \mu M$ the CD signal disappeared in all cases, supporting the formation of a solid phase. Further, additions of aminooxy polyamine did not provoke significant alterations in the CD spectra.

The important CD features described above led us to investigate the influence of this aminooxy 

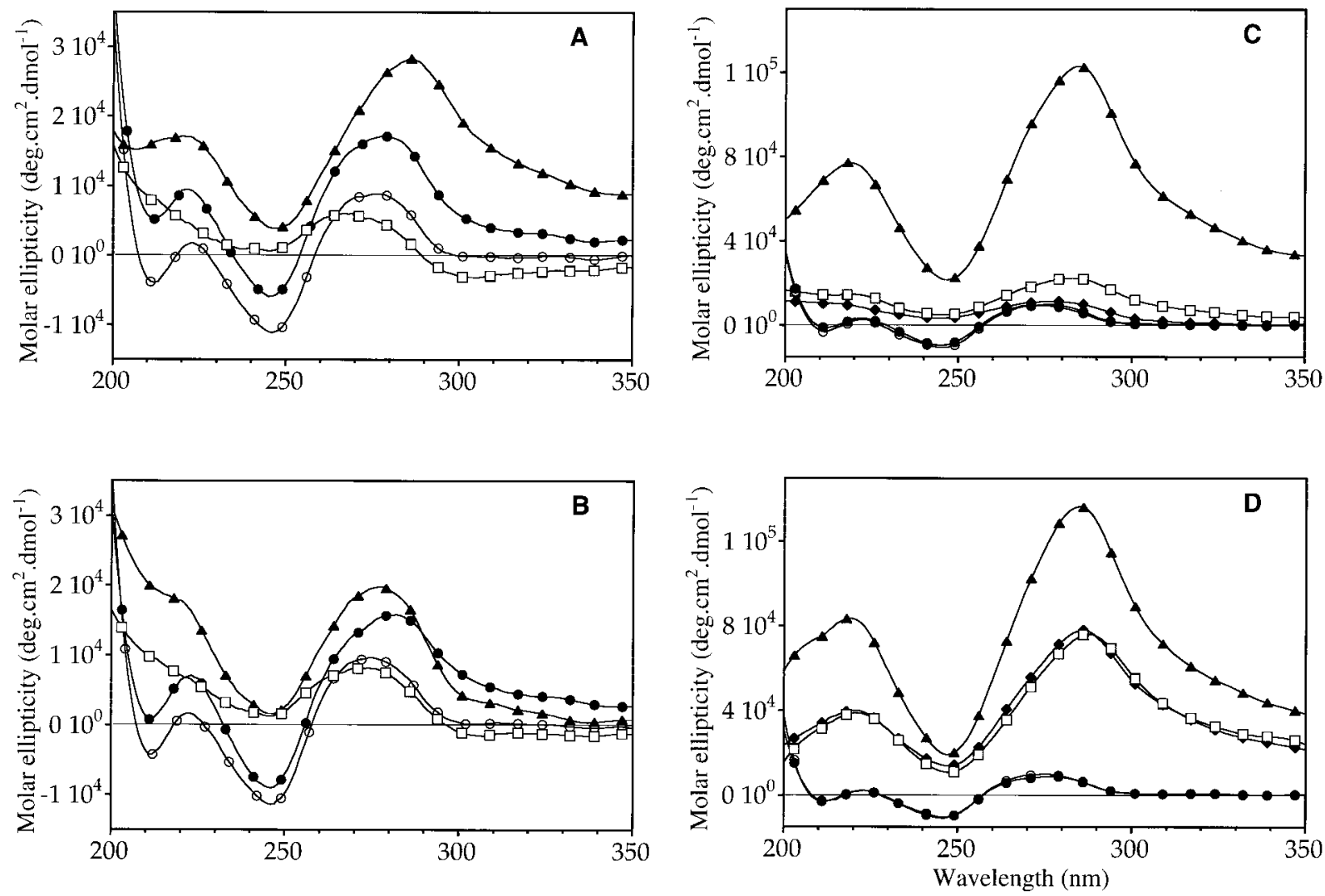

Figure 2. The CD spectra of sonicated calf thymus DNA with $10 \mathrm{~m} M$ Tris-HCl at $\mathrm{pH}$ values of (A) 5 , (B) 6 , (C) 7, and (D) 7.5 in the presence of AOSPM concentrations of $(O)$

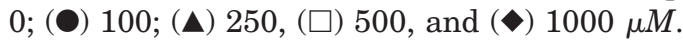

polyamine in the thermal stability of DNA. Figure 4 shows the melting curves for solutions containing sonicated CT-DNA in the presence of AOSPM at physiological $\mathrm{pH}$. The melting temperature increased with increasing AOSPM concentration; the $T_{m}$ values were $66.4^{\circ} \mathrm{C}$ for the control and 86.2 and $95.6^{\circ} \mathrm{C}$ for samples containing 100 and 250 $\mu M$ AOSPM, respectively. DNA solutions containing 250 and $500 \mu M$ AOSPM also showed small absorbance increases at room temperature compared to the control CT-DNA solution. In the presence of $500 \mu M$ AOSPM, the absorbance at $260 \mathrm{~nm}$ monotonically decreased with increasing temperature from 30 to $80^{\circ} \mathrm{C}$ and stabilized between 80 and $100^{\circ} \mathrm{C}$. This could be a consequence of DNA condensation or precipitation.

\section{Spermidine Aminooxy Analogues APAPA and AOEPUT}

The CD spectra of sonicated CT-DNA with different concentrations of APAPA and AOEPUT and
$\mathrm{pH}$ values ranging from 5 to 7.5 , are displayed in Figure 5 and 6 , respectively. These spermidine analogues are dications at physiological $\mathrm{pH}$ and, as described for AOSPM, their molecular charges increased with decreased $\mathrm{pH}$.

Regarding the CD spectra of DNA/APAPA at pH 5 [Fig. 5(A)], the positive DNA bands at 222 and $276 \mathrm{~nm}$ showed a significant increase in the molar ellipticity at APAPA concentrations of 500 and $1000 \mu M$. Lower concentrations did not induce significant changes. This behavior was accompanied by a blueshift of the three DNA bands at 270,240 , and $209 \mathrm{~nm}$. No precipitation phenomena were observed under our experimental conditions. At pH 6 [Fig. 5(B)] an intensity increase was observed only for the $1000 \mu M$ solution, while the $\mathrm{CD}$ spectra at $\mathrm{pH} 7$ and 7.5 did not increase with the APAPA concentration. However, the peak intensity of the three DNA CD bands slightly decreased with increasing analogue concentrations.

As shown in Figure 6, the CD spectra of CT- 

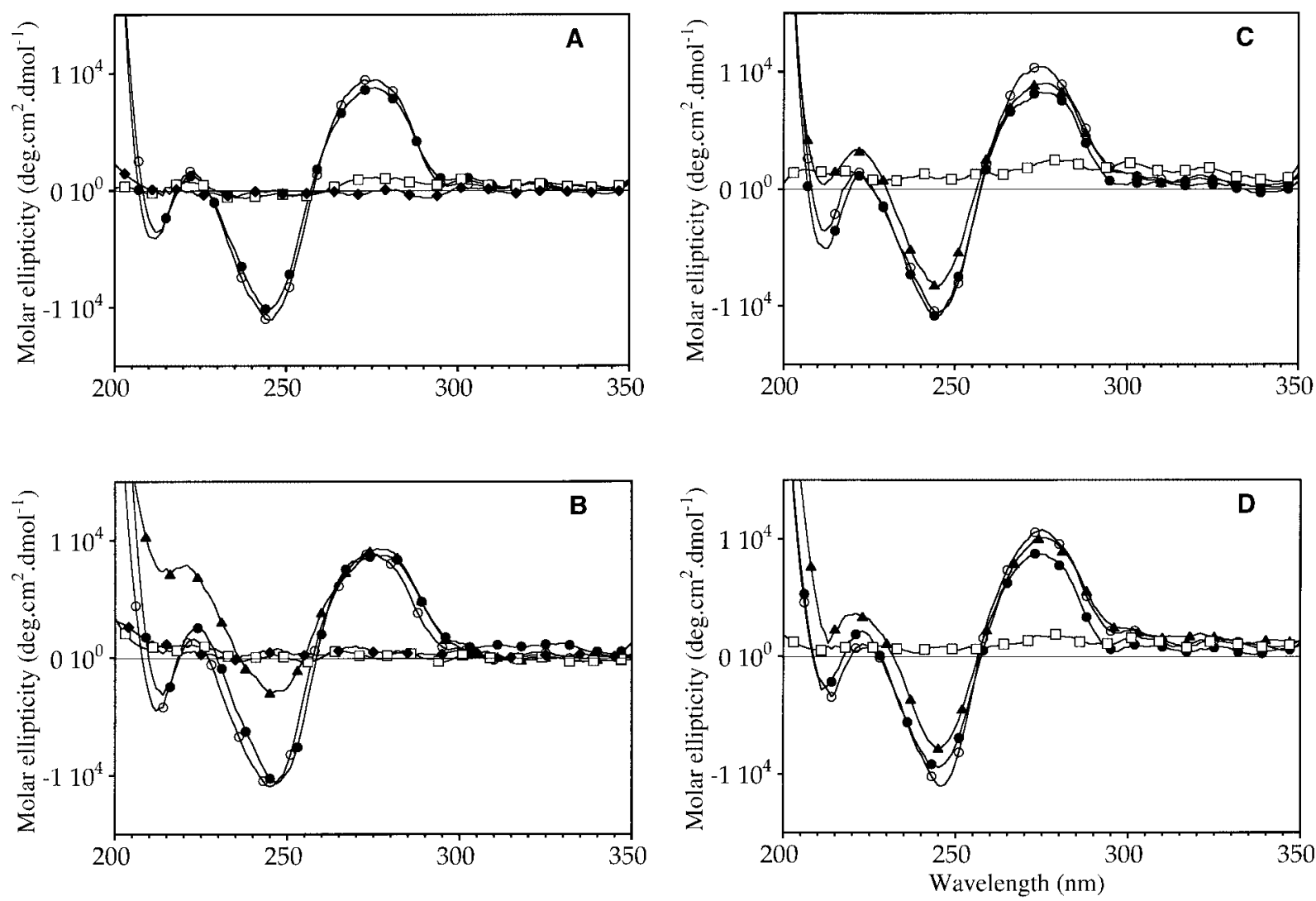

Figure 3. The CD spectra of highly polymerized calf thymus DNA with $10 \mathrm{mM}$ Tris- $\mathrm{HCl}$ at $\mathrm{pH}$ values of (A) 5, (B) 6, (C) 7, and (D) 7.5 in the presence of AOSPM concentrations of $(\bigcirc)$, ( $100,(\Delta) 250,(\square) 500$, and $(\bullet) 1000 \mu M$.

DNA/AOEPUT solutions did not show any increase in intensity within both $\mathrm{pH}$ and concentration ranges examined. At $\mathrm{pH} 7$ and 7.5 AOEPUT is a dication, and the spectra did not show major

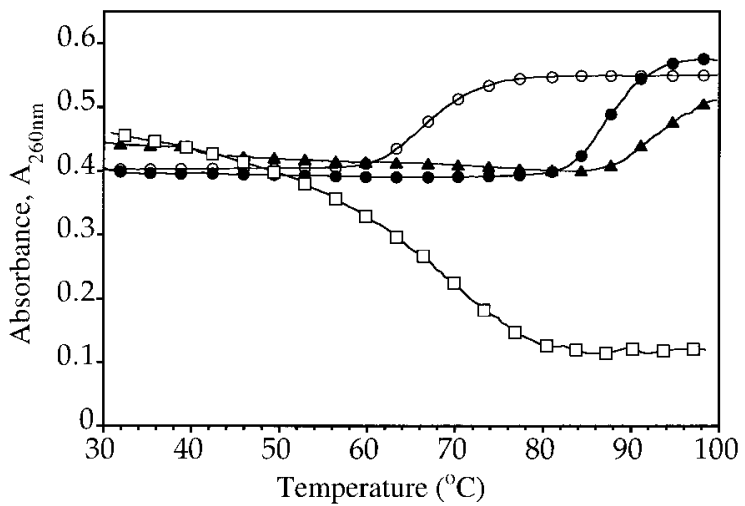

Figure 4. The melting temperature profiles of sonicated calf thymus DNA with $10 \mathrm{mM}$ Tris-HCl at physiological $\mathrm{pH}$ in the presence of AOSPM concentrations

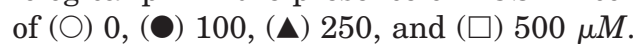

changes by adding this aminooxy polyamine up to $1000 \mu M$. However, at low $\mathrm{pH}$ values (5 and 6) the CD signal almost disappeared at a $1000 \mu M$ AOEPUT concentration, indicating DNA precipitation.

Finally, we also recorded the CD spectra of HP CT-DNA in the presence of APAPA and AOEPUT. With AOEPUT (Fig. 7) the results did not show significant deviations with respect to those obtained for sonicated DNA. The CD spectra of APAPA and HP CT-DNA also followed similar trends. As discussed below, this behavior correlates well with that observed from HP CT-DNA/ AOSPM solutions (Fig. 3) and with the protonation equilibrium of the aminooxy moiety.

\section{DISCUSSION}

The CD spectra of DNA-AOSPM solutions showed significant increases in intensity with increasing aminooxy polyamine concentration, which, in 

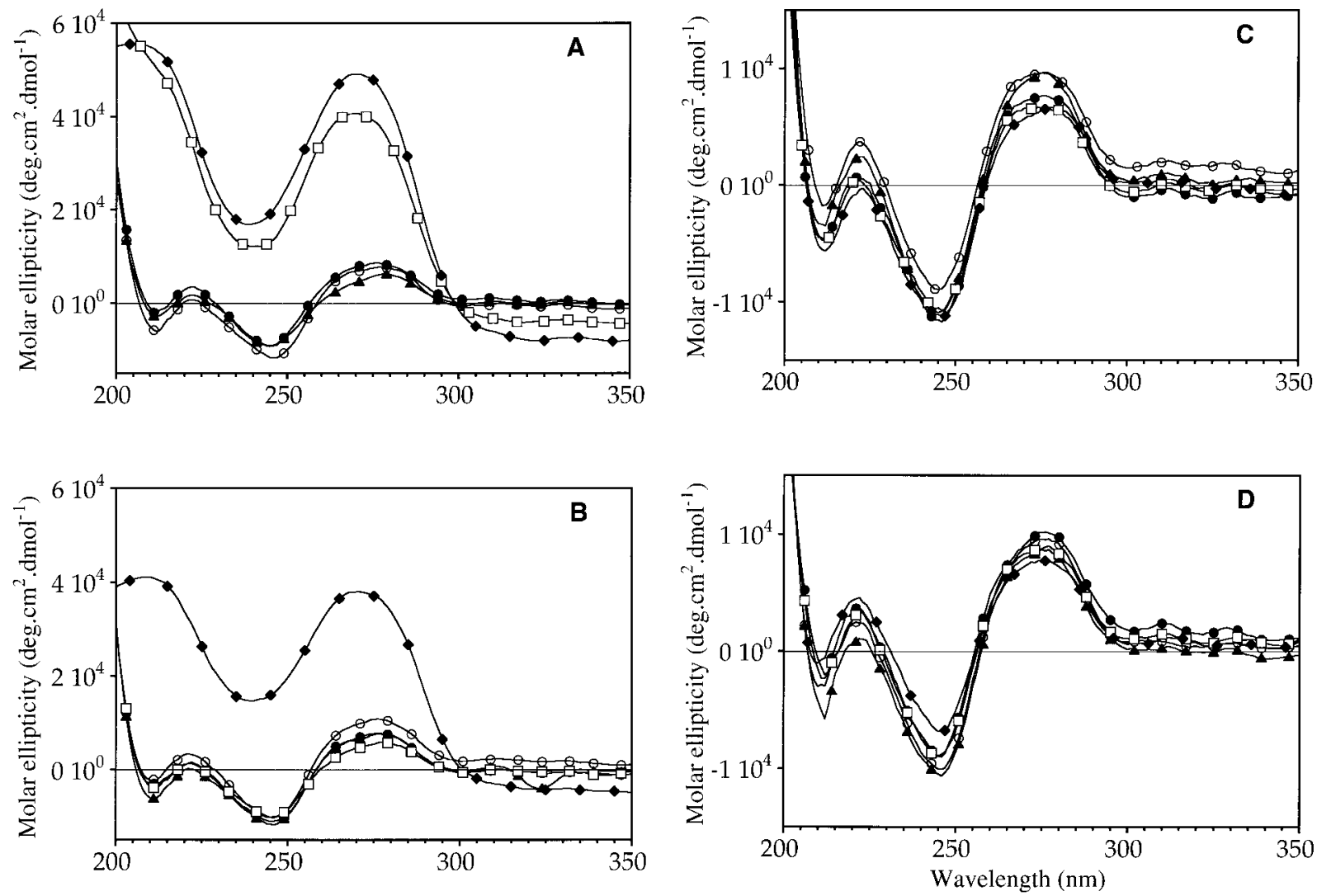

Figure 5. The CD spectra of sonicated calf thymus DNA with $10 \mathrm{~m} M$ Tris-HCl at $\mathrm{pH}$ values of (A) 5, (B) 6, (C) 7, and (D) 7.5 in the presence of APAPA concentrations of (O)

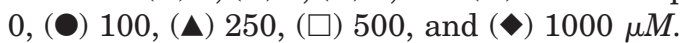

some cases, was followed by DNA precipitation. This phenomenon is interpreted as the formation of a tertiary structure described as a highly ordered, liquid-crystal like form of DNA, ${ }^{28-32}$ which is termed $\Psi$-DNA (psi for polymer and salts induced). ${ }^{33}$ The characteristic CD spectrum of $\Psi$-DNA arises because the interaction of circularly polarized light with the polymer can no longer be described from the nearest neighbor contributions, ${ }^{34}$ but new long-range terms are introduced. ${ }^{27}$ The transition from B-DNA to $\Psi$-DNA is usually manifested by DNA aggregation. However, it is important to note the difference between aggregation and precipitation; while aggregates are described as anisotropic, fluid phases in solution, ${ }^{29}$ precipitates are out of solution, solid phases. Several in vitro studies demonstrated the ability of both short and long DNA chains to form condensed states in the presence of polycations ${ }^{35,36}$ : these condensates remain in solution when the DNA concentration is on the micromolar order. Recently, the fine characteristics of dif- ferent DNA condensates in the presence of the biogenic polyamine spermine were investigated by microscopy techniques, ${ }^{37}$ which indicated that the DNA aggregates formed in very dilute solutions had a liquid crystalline structure. The biological importance of aggregates comes from aggregation being required for transfection of oligonucleotides in living cells ${ }^{38-40}$ and for catenation of DNA to topoisomerases. ${ }^{41}$ This fact enhances the role of biogenic polyamines in vivo.

Although the electronic absorbance is directly sensitive only to base stacking, ${ }^{42}$ breaking of hydrogen bonds is a prerequisite to base unstacking. The melting profiles shown in Figure 4 therefore demonstrate that the aggregate formation enhances the forces that hold the two DNA strands together (base pairing and base stacking). The small increases in the absorbance observed for the 250 and $500 \mu M$ AOSPM solution at room temperature would indicate that the stacking forces were slightly relaxed as a consequence of aggregation, although the influence of solvation 

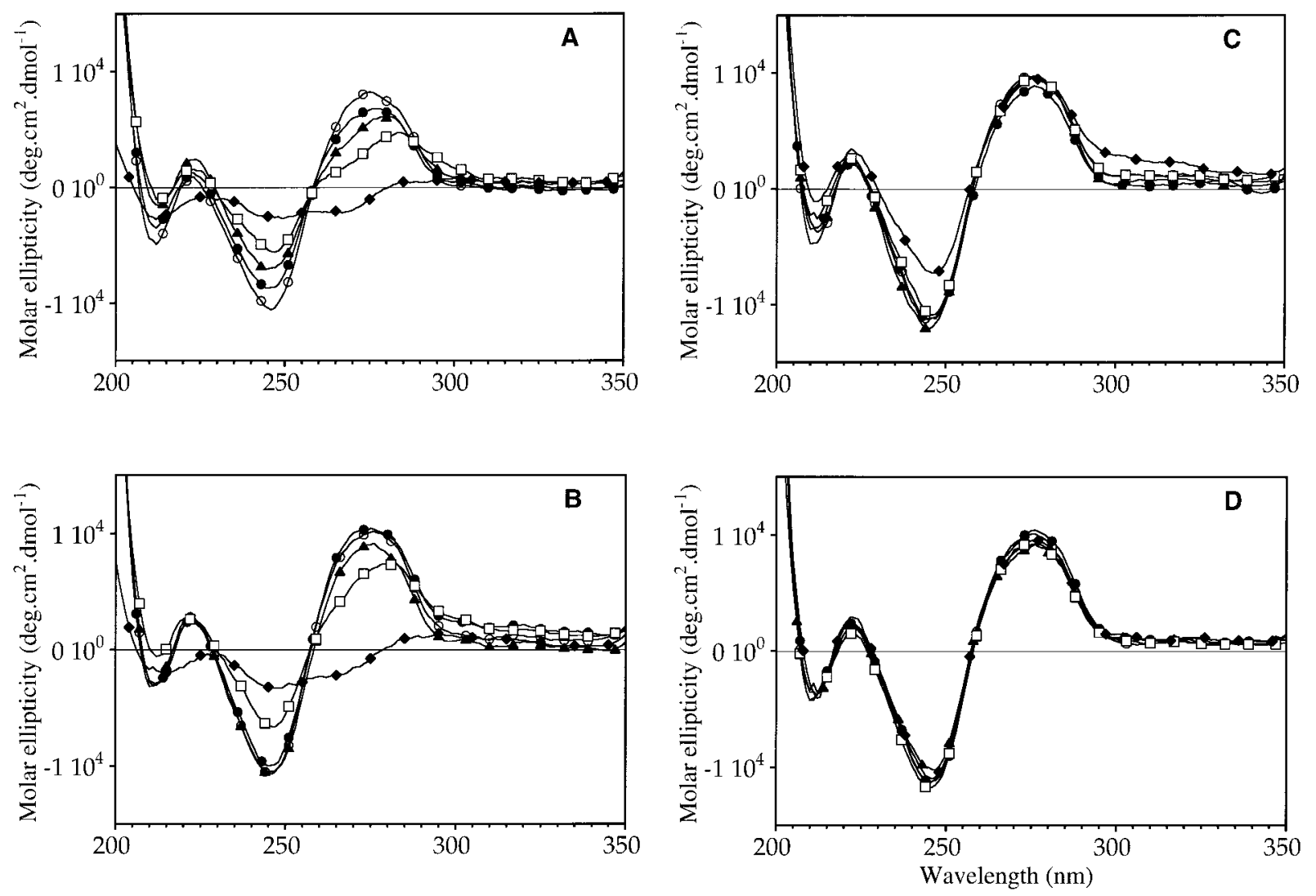

Figure 6. The CD spectra of sonicated calf thymus DNA with $10 \mathrm{~m} M$ Tris- $\mathrm{HCl}$ at $\mathrm{pH}$ values of (A) 5, (B) 6, (C) 7, and (D) 7.5 in the presence of AOEPUT concentrations of (O)

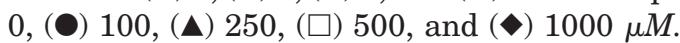

effects in DNA cannot be discarded. The solution at $500 \mu M$ AOSPM concentration exhibited a decrease in the absorbance by increasing the temperature. Because this result cannot be originated by a DNA duplex stabilization at high temperatures, it could be better attributed to a thermally favored aggregation or precipitation of DNA, which settled to the bottom of the cell, thereby reducing the absorbance of the solution phase. On the other hand, an increase in the temperature will favor states with higher entropy content, which could be interpreted because the cholesteric phase reaches a more ordered state than the precipitated phase, at least under our experimental conditions.

A comparison of the CD spectra of AOSPM with sonicated and HP-DNA indicates that aggregation is more favored from short chains than from long chains of DNA. As can be observed in Figure 3, none of the CD spectra of HP-DNA suggested the formation of aggregated structures; the only effect we could see is DNA precipitation when augmenting the aminooxy polyamine concentration. A similar behavior was observed for the aminooxy analogues of spermidine. It is easy to imagine that intramolecular interactions will be dominant for long CT-DNA while intermolecular interactions will be dominant for short DNA. As a consequence, short DNA fragments will be less sterically hindered to fold in larger ordered macrostructures in the presence of polycations. Previous studies on DNA-daunomycin complexes supported this statement with the use of different sonication times. ${ }^{27}$ In the case of HP-DNA, polycations would induce aggregation on specific sequences with significant biological importance, which would restrict further folding or packaging of neighbor sequences. This partial folding would not be enough to originate a CD signal increase, which is what happens when sonicated DNA is employed. Thus, long DNA chains undergo precipitation without adopting an intermediate aggregate form.

The influence of the aminooxy polyamine 

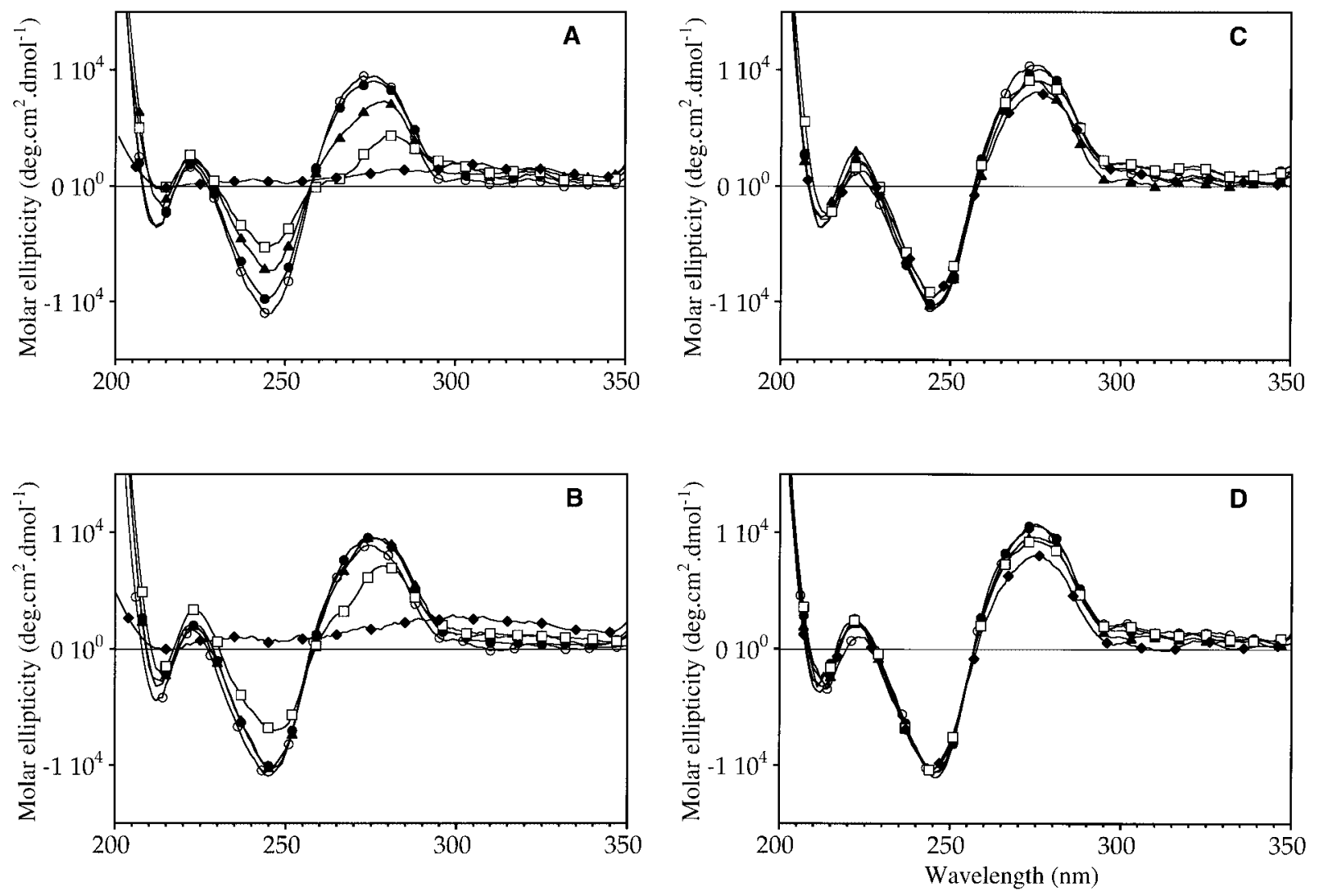

Figure 7. The CD spectra of highly polymerized calf thymus DNA with $10 \mathrm{mM}$ Tris-HCl at $\mathrm{pH}$ values of (A) 5, (B) 6, (C) 7, and (D) 7.5 in the presence of AOEPUT

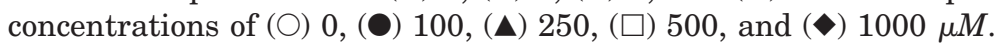

charge on the interaction of these analogues with DNA can be derived from changes in the CD spectra at different $\mathrm{pH}$ values. The $\mathrm{CD}$ spectra of $\mathrm{HP}$ CT-DNA and AOEPUT (Fig. 3) show that at a lower $\mathrm{pH}$, which increases the protonation of the aminooxy compound, precipitation requires lower concentrations. In addition, no precipitation was observed for the spermidine analogue at $\mathrm{pH}$ values higher than 6 , when it was a dication. This result shows that dications cannot precipitate DNA, in agreement with previous works. ${ }^{43-45}$ The influence of the positive charge can also be evaluated from the CD spectra of sonicated DNA (Figs. 2, 5, and 6). The aminooxy analogues APAPA and AOEPUT were unable to provoke relevant macromolecular changes in the DNA at $\mathrm{pH}$ values higher than 6 , while they induced aggregation (APAPA) or precipitation (AOEPUT) at $\mathrm{pH} 5$ and 6. Concerning AOSPM, which is a trication at physiological $\mathrm{pH}$, the $\mathrm{CD}$ spectra in (Figure $2 \mathrm{C}, \mathrm{D}$ ) show an increase in the molar ellipticity when the aminooxy polyamine concentration reaches $250 \mu M$. Further addition of AOSPM did not condense sonicated CT-DNA into a solid precipitate under our experimental settings. However, at $\mathrm{pH} 5$ and 6 [Fig. 2(A,B)], aggregation was followed by a complete precipitation of DNA at a concentration of $1000 \mu M$. Summarizing, our CD spectra prove that dications do not induce major macromolecular changes on both sonicated and HP-DNA. Molecules with a higher charge can induce either aggregation or precipitation at suitable concentrations, depending on the structural specificities.

The aminooxy polyamines allow us to study the structural specificities involved in DNA aggregation-precipitation. The CD spectra shown in Figures 2(D), 5(A), and 6(A) indicate that molecules having a charge higher than +2 can originate macromolecular effects on sonicated DNA. However, at $\mathrm{pH} 5$ AOEPUT induced DNA precipitation while APAPA induced DNA aggregation. Both aminoxy polyamines are isosteric of spermidine; however, N1 nitrogen is charge deficient in 
the case of AOEPUT, while N8 nitrogen is charge deficient in the case of APAPA. The observed difference in the effects of AOEPUT and APAPA is the direct indication of the nonequivalent contribution of the N1 and N8 amino groups of spermidine in the interaction with DNA. On the other hand, an APAPA molecule always presents trimethylene chains between two positive charges, which are separated by two and four methylene groups in AOEPUT. As shown in Figure 1, AOSPM also presents a trimethylene moiety, having a positive charge distribution along the molecular chain that is rather similar to the fully protonated APAPA. The CD spectra indicated aggregate formation for the AOSPM and APAPA solutions but not for the AOEPUT solutions. However, the more intense CD signal was obtained at $250 \mu M$ for AOSPM ( $\mathrm{pH}$ 7.5) and at $1000 \mu M$ for APAPA (pH 5). Concentrations of AOSPM greater than $250 \mu M$ originated a decrease in the molar ellipticity, without observing precipitation up to $1000 \mu M$. Because both molecules have the same charge at their corresponding experimental conditions, these differences have to have originated from the different molecular weight and/or from the aminooxy group. The $\mathrm{O}-\mathrm{NH}_{2}$ group does not have a net charge for AOSPM at $\mathrm{pH}$ 7.5; however, the lone pair of the heteroatoms could act as a nucleophilic reactive, so that they would be able to interact with DNA sites having an electron defect (acidic hydrogens, etc.).

The CD spectra obtained for AOSPM (Fig. 2) can be compared to those reported for sonicated CT-DNA in the presence of biogenic polyamine spermine at physiological $\mathrm{pH}^{46}$ The spectra of DNA/AOSPM at $\mathrm{pH} 5$ and DNA/spermine at physiological $\mathrm{pH}$ exhibit similarities. As an example, the strong CD band of DNA at $276 \mathrm{~nm}$ was shifted to higher wavelengths with increasing intensity by adding both polyamines, reaching maximal molar ellipticity values between (2 and 3 ) $\times 10^{4} \mathrm{deg} \mathrm{cm}{ }^{2} \mathrm{dmol}^{-1}$. However, greater concentrations were necessary for AOSPM than for spermine to reach a similar CD increase; as a consequence, the maximal CD signal was reached at a spermine concentration of $50 \mu M$ while for AOSPM a concentration of $250 \mu M$ was required. On the other hand, characteristic CD spectra of $\Psi$-DNA are reported for long DNA chains in the presence of spermine, ${ }^{47}$ which are different from those observed for HP CT-DNA/AOSPM solutions at low $\mathrm{pH}$ values [Fig. 3(A,B)]. These observations enhance the functional differences between a partially protonated aminooxy group and a fully pro- tonated amino group, thus supporting the role of the structural specificities in the DNA-polyamines interaction.

Studies on DNA condensation in the presence of trication spermidine ${ }^{46,48-50}$ demonstrated the efficiency of this biogenic polyamine as a precipitating or aggregating agent. It was also reported that the biogenic polyamine putrescine, which is a dication at physiological $\mathrm{pH}$, is unable to induce major changes in the macromolecular structure of DNA. ${ }^{48,51}$ This fact is compatible with the present results. Thus, DNA condensation or aggregation was observed for AOSPM at physiological $\mathrm{pH}$, while for the spermidine aminooxy analogues we only observed macromolecular effects at low $\mathrm{pH}$ values.

In summary, the aminooxy analogues of polyamines can induce aggregation and/or precipitation on DNA with increasing concentration. Formation of $\Psi$-DNA was only observed with sonicated DNA under our experimental conditions. Precipitation was observed with both sonicated and HP-DNA. Partial folding could be possible for HP-DNA, although this was not detected from our CD spectra. These processes were generally enhanced when increasing the charge of the analogues. Neither precipitation nor aggregation was observed for dications. Compounds with higher molecular charges were capable of provoking aggregation, depending on their molecular structure. Our CD results indicated that aggregation was only induced when the trimethylene moiety was placed between two adjacent positive charges. Otherwise, sonicated DNA precipitated without adopting a previous aggregated structure. The CD studies also indicate that primary amino end groups of the biogenic polyamine spermidine could have differential interactions with DNA.

The authors gratefully thank Dr. Alexander R. Khomutov (Russian Academy of Sciences, Moscow) for providing the aminooxy polyamines and for his useful advice. The first author (F.R.J.) thanks the University of Málaga, which supported his stay at the Robert Wood Johnson Medical School.

\section{REFERENCES}

1. Tabor, H.; Tabor, C. W. Annu Rev Biochem 1984, 53, 749-790.

2. Pegg, A. E. Cancer Res 1988, 48, 759-774. 
3. Heby, O.; Persson, L. Trends Biochem Sci 1990, 15, 153-158.

4. McMurry, L. M.; Algranati, I. D. Eur J Biochem 1986, 155, 383-390.

5. Janne, J.; Alhonen, L., Leinonen, P. Ann Med 1991, 23, 241-259.

6. Ha, H. C.; Woster, P. A.; Yager, J. D.; Casero, R. A., Jr. Proc Natl Acad Sci USA 1997, 94, 11557-11562.

7. Ha, H. C.; Yager, J. D.; Woster, P. A.; Casero, R. A., Jr. Biochem Biophys Res Commun 1998, 244, $298-$ 303.

8. Sy, D.; Hugot, S.; Savoye, C.; Ruiz, S.; Charlier, M.; Spotheim-Maurizot, M. Int J Radiat Biol 1999, 75, 953-961.

9. Braunlin, W. N.; Strick, T. J.; Record, M. T., Jr. Biopolymers 1982, 21, 1301-1314.

10. Raspaud, E.; Olvera de la Cruz, M.; Sikorav, I.; Livolant, F. Biophys J 1998, 74, 381-393.

11. Thomas, T. J.; Bloomfield, V. A. Biopolymers 1984, 23, 1295-1306.

12. Feuerstein, B. J.; Williams, L. D.; Basu, H. S.; Marton, L. J. J Cell Biochem 1991, 46, 37-47.

13. Deng, H.; Bloomfield, V. A.; Benevides, J. M.; Thomas, G. J., Jr. Nucl Acid Res 2000, 28, 3379_ 3385.

14. Ruiz-Chica, J.; Medina, M. A.; Sánchez-Jiménez, F.; Ramírez, F. J. Biophys J 2001, 80, 443-454.

15. Ruiz-Chica, J.; Medina, M. A.; Sánchez-Jiménez, F.; Ramírez, F. J. Biochem Biophys Res Commun 2001, 285, 437-446.

16. Hamana, K.; Hamana, H.; Niitsu, M.; Samejima, K.; Itoh, T. Microbios 1996, 85, 19-33.

17. Khomutov, A. R.; Khomutov, R. M. Khim 1989, 15, 698-703.

18. Khomutov, A. R.; Vepsalainen, J.; Shvetsov, A. S.; Hyvönen, T.; Keinanen, T. A.; Pustobaev, V. N.; Eloranta, T. O.; Khomutov, R. M. Tetrahedron 1996, 52, 13751-13766.

19. Khomutov, R. M.; Denisova, G. F.; Khomutov, A. R.; Belostotskaya, K. M.; Shlosman, R. B.; Artamonova, E. Y. Bioorg Khim 1985, 11, 1574-1576.

20. Hyvönen, T.; Alakuijala, L.; Andersson, L. C.; Khomutov, A. R.; Khomutov, R. M.; Eloranta, T. O. J Biol Chem 1988, 263, 11138-11144.

21. Eloranta, T. O.; Khomutov, A. R.; Khomutov, R. M.; Hyvönen, T. J Biochem 1990, 108, 593-598.

22. Hyvonen, T.; Keinanen, T. A.; Khomutov, A. R.; Khomutov, R. M.; Eloranta, T. O. Life Sci 1995, 56, 349-360.

23. Khomutov, A. R.; Shvetsov, A. S.; Vepsalainen, J.; Hyvönen, T.; Keinanen, T. A.; Eloranta, T. O.; Kramer, D. L.; Porter, C. W.; Khomutov, R. M. Bioorg Khim 1996, 22, 557-559.

24. Fukudome, K.; Yamaoka, K.; Nishikori, K.; Takahashi, T.; Yamamoto, O. Polym J 1986, 18, 71-79.

25. Thomas, T. J.; Bloomfield, V. A. Biochemistry 1985, 24, 713-719.
26. Sprecher, C. A.; Baase, W. A.; Johnson, W. C., Jr. Biopolymers 1979, 18, 1009-1019.

27. Bustamante, C.; Samori, B.; Builes, E. Biochemistry 1991, 30, 5661-5666.

28. Cowman, M. K.; Fasman, G. D. Proc Natl Acad Sci USA 1978, 75, 4759-4763.

29. Zacharias, W.; Martin, J. C.; Wells, R. D. Biochemistry 1983, 22, 2398-2405.

30. Phillips, C. L.; Mickols, W. E.; Maestreand, M. F.; Tinoco, L., Jr. Biochemistry 1986, 25, 7803-7811.

31. Livolant, F.; Levelut, A. M.; Doucet, J.; Benoit, J. P. Nature 1989, 339, 457-460.

32. Leforestier, A.; Livolant, F. Biophys J 1997, 73, 1771-1776.

33. Lerman, L. S. Proc Natl Acad Sci USA 1971, 68, 1886-1890.

34. Gray, D. M.; Tinoco, I., Jr. Biopolymers 1970, 9, 223-244.

35. Bloomfield, V. A. Biopolymers 1991, 31, 1471-1481.

36. Sikorav, J. L.; Pelta, J.; Livolant, F. Biophys J 1994 67, 1378-1392.

37. Lin, Z.; Wang, C.; Feng, X.; Liu, M.; Li, J.; Bai, C. Nucl Acid Res 1998, 26, 3228-3234.

38. Pitard, B.; Aguerre, O.; Airiau, M.; Lachages, A. M.; Boukhnikachvili, T.; Byk, G.; Dubertret, C.; Herviou, C.; Scherman, D.; Majaux, J. F.; Crouzet, J. Proc Natl Acad Sci USA 1997, 94, 14412-14417.

39. Lappalainena, K.; Miettinenb, R.; Kellokoskic, J.; Jääskeläinend, I.; Syrjänena, S. J Histochem Cytochem 1997, 45, 265-274.

40. Meyer, O.; Kirpotin, D.; Hong, K.; Sternberg, B.; Park, J. W.; Woodle, M. C.; Papahadjopoulos, D. J Biol Chem 1998, 273, 15621-15627.

41. Krasnow, M. A.; Cozzarelli, N. R.; J Biol Chem 1982, 257, 2687-2693.

42. Van Holde, H. E.; Johnson, W. C.; Ho, P. S. Principles of Physical Biochemistry; Prentice-Hall: Englewood Cliffs, NJ, 1998; pp 166-178.

43. Lyubartsev, A. P.; Nordenskiöld, L. J Phys Chem 1995, 99, 10373-10382.

44. Bloomfield, V. A. Biopolymers 1997, 44, 269-282.

45. Rouzina, I.; Bloomfield, V. A. Biophys J 1998, 74, 3152-3164.

46. Saminathan, M.; Antony, T.; Shirahata, A.; Sigal, L. H.; Thomas, T.; Thomas, T. J. Biochemistry 1999, 38, 3821-3830.

47. Becker, M.; Misselwitz, R.; Damaschun, H.; Damaschun, G.; Zirwer, D. Nucl Acid Res 1979, 7, 1297 1309.

48. Thomas, T. J.; Messner, R. P.; Nucl Acid Res 1986, 16, 6721-6733.

49. Schellman, J. A.; Parthasarathy, N. J Mol Biol 1984, 175, 313-329.

50. Pelta, J.; Livolant, F.; Sikorav, J. L.; J Biol Chem 1996, 271, 5656-5662.

51. Thomas, T.; Kulkarni, G. D.; Gallo, M. A.; Greenfield, N.; Lewis, J. S.; Shirahata, A.; Thomas, T. J. Nucl Acid Res 1997, 25, 2396-2402. 